\title{
International Journal of Mechanical and Industrial Engineering
}

October 2013

\section{A STUDY ON DEVELOPMENT OF INDUSTRIAL TRIBOLOGY IN INDIA WITH SOME FUTURE PROSPECTS}

\author{
VIVEK SINGH \\ Deptt. of Mechanical Engineering, MITS, Gwalior, India, 1987rjit.vivek@gmail.com \\ JYOTI VIMAL \\ Department of Mechanical Engineering, Madhav Institute of Technology \& Science, Gwalior, Gwalior, India, \\ jyoti_vimal@yahoo.com
}

Follow this and additional works at: https://www.interscience.in/ijmie

Part of the Manufacturing Commons, Operations Research, Systems Engineering and Industrial Engineering Commons, and the Risk Analysis Commons

\section{Recommended Citation}

SINGH, VIVEK and VIMAL, JYOTI (2013) "A STUDY ON DEVELOPMENT OF INDUSTRIAL TRIBOLOGY IN INDIA WITH SOME FUTURE PROSPECTS," International Journal of Mechanical and Industrial Engineering: Vol. 3 : Iss. 2 , Article 10. DOI: $10.47893 / I J M I E .2013 .1140$

Available at: https://www.interscience.in/ijmie/vol3/iss2/10

This Article is brought to you for free and open access by the Interscience Journals at Interscience Research Network. It has been accepted for inclusion in International Journal of Mechanical and Industrial Engineering by an authorized editor of Interscience Research Network. For more information, please contact sritampatnaik@gmail.com. 


\title{
A STUDY ON DEVELOPMENT OF INDUSTRIAL TRIBOLOGY IN INDIA WITH SOME FUTURE PROSPECTS
}

\author{
VIVEK SINGH, JYOTI VIMAL ${ }^{1}$ \& VEDANSH CHATURVEDI ${ }^{2}$
}

\author{
${ }^{1,2}$ Deptt. of Mechanical Engineering, MITS, Gwalior, India \\ E-mail : 1987rjit.vivek@gmail.com, Jyoti_vimal@yahoo.com
}

\begin{abstract}
The Indian industry is facing tough challenges from various others countries in different areas. Environmental challenges, government pressure to improve efficiencies, urgent technological advancement requirement, emission cut from tribological and lubricating systems. A brief review of industrial development in India is outlined in this paper. I will also discuss about fields of tribology like Engine Tribology, Green Tribology, Transmission Tribology and Tire Tribology with some suggestions. Role of education in tribology to makes a balance between technology and environment. At lasts a review on future trends in industrial tribology.
\end{abstract}

Keywords - India, industrial tribology, engine, green, transmission, tire, future trends.

\section{INTRODUCTION}

The first recognition on importance of the tribology applications is by the British "jost Report" in which it was mentioned that improvement in lubrication and maintenance in industry could save their economy. Tribological activities started in India after independence. In new India self reliance, especially infrastructure in fields of power, manufacturing, automobile, agriculture, mining, electricity, pharmaceutical and education was to be attained. A proper plan only leads to the point of achieving the proposed desire. The then government worked out five year plan and implements it. First five year plan helps in achieving the desired result in agriculture. Second was for industry development. All the visions were implemented simultaneously i.e. industrial development, development of laboratory for nation and research and development in education sector. Appropriate steps were taken at right juncture. Still our country was not able to match with the pace of the world. Our country lacks behind the world by quite a margin. After introduction of liberal economic policy, we have started to move on the right track.

\section{INDUSTRY}

Our approach was focused much on development of heavy industry, and that need great investment but due to 250 years of colonial rule our condition was not in good shape. International support was also minimal initially. So the whole focus was shifted towards maintenance work. It was how tribology entered Indian arena. We have to maintain performance of our machines by shop floor based prognosis and repair. Thus first phase of development of tribology in India consisted of committed work by shop floor workers, supervisors in various sectors such as railways and ordinance factory to keep machineries in good order and running [1]. In the second phase, tribology was considered as a useful and relevant. It was given a due credit and major industries started tribology sections and departments as important service units in their backyards. BHEL was the first one to recognize it and started a department of tribology for analyzing its journal and bearings failure used in rotating machineries. An important lesson was learnt from this analysis that if failures detected earlier can prolonged the life of the machineries. This small starting has now taken a shape of full Failure Analysis Group.

The industry today synthesizes lubricant molecules and is a major player in this field in the world. But now certainly industries have to focus much on biodegradable lubricants. To initiate and boost the use of biodegradable products, government incentives and mandatory regulations are needed to put pressure on industries that releases lubricant into environment. The various biodegradable lubricants available are [2]:

- Highly unsaturated or high oleic vegetable oils (HOVOs),

- Low viscosity polyalphaolefins (PAOs),

- Polyalkylene glycols (PAGs),

- Dibasic acid esters (DEs),

- Polyol esters (PEs)

This increasing attention to the environmental issues and more restrictive environmental regulations drives the lubricant industry to increase the ecological friendliness of its products. For last few decades industries has been trying to make environmentally adopted lubricants with technical characteristics equal or superior to other mineral oils. Vegetable oils are more suitable as replacement since it is biodegradable, non toxic as well as has good technical characteristics as required. Secondly India being agriculture based country it is ideal suit for agriculture equipments. The cost of these vegetable oils is reasonable to other biodegradable fluids. 
Universal tractor transmission oil is multipurpose oil widely used in agriculture equipments.

\section{ENGINE TRIBOLOGY}

Recent study estimated that the cost of friction and wear in India is Rs.78.67 billion and 55-60\% of equipment damage is caused by poor lubrication and severe wear. India has grown as the fourth largest consumer of automobile in world. Vehicle population has reached 21 million in India in 2011. With this increase consumption of auto lubricant also increases. Better fuel- efficient vehicles and higher energy conserving engine oils will become increasingly important in the face of saving of natural resources and lowering of engine friction. The application of Tribological principles is essential for reliability of motor vehicle, in order to reduce friction and wear, with minimum adverse impact on environment. This task is not so simple taking in view the wide range of operating conditions of speed, load and temperature in an engine.

Improvement in Tribological performance of engine can provide following benefits [3]:

- Increased engine power output

- Reduced fuel consumption

- Reduction in harmful exhaust emissions

- Improved engine durability and its life.

- Reduced maintenance requirements and longer service intervals.

According to a survey [3] $48 \%$ of energy consumption developed in an engine is done by friction loss. With such large number of engine in service in India, even a smallest change in engine efficiency, durability and emission level can have a great impact on the world fuel economy and environment. Therefore, it is in urgent need for advanced engine Tribological design and high performance and environmental friendly lubricants.

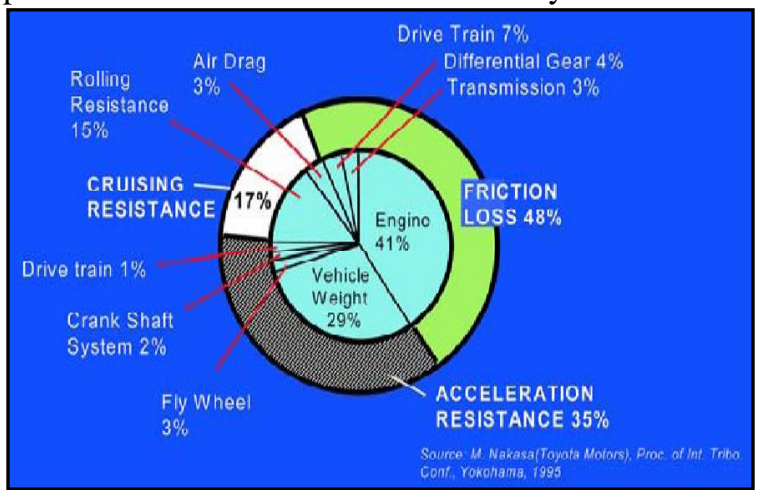

Fig. 1 : Energy consumption of engine.

\section{GREEN TRIBOLOGY}

Recently, the new concept of 'green tribology' has been defined as 'the science and technology of the tribological aspects of ecological balance and of environmental and biological impacts'. The specific field of green or environment-friendly tribology emphasizes the aspects of interacting surfaces in relative motion, which are of importance for energy or environmental sustainability or which have impact upon today's environment. This includes tribological technology that mimics living nature (biomimetic surfaces) and thus is expected to be environment friendly, the control of friction and wear, which is of importance for energy conservation and conversion, environmental aspects of lubrication and surfacemodification techniques and tribological aspects of green applications, such as wind-power turbines, tidal turbines or solar panels. It is clear that a number of tribological problems could be put under the umbrella of green tribology and are of mutual benefits to one another. Green tribology can be seen from broader context by two other green areas: Green engineering and green chemistry. Green engineering is defined as the 'The design, commercialization and use of processes and products that are technically and economically feasible while mitigating the pollution of the source and minimizing the health and safety problems. Green chemistry is defined as the design of chemical products and processes that reduce or eliminate the use or generation of hazardous substances. Green chemistry technologies provide a number of benefits like waste reduction, eliminating costly end-of-the-pipe treatments, safer products, less use of energy and resources and enhancement in competitiveness of chemical manufacturers and their customers. The twelve principles of Green tribology as laid down in green tribology by M. Nosonovsky and B. Bhushan[4].

- Minimization of heat and energy dissipation.

- Minimization of wear.

- Reduction or elimination of lubrication and self lubrication.

- Natural lubrication should be used.

- Biodegradable lubrication should be used.

- Sustainable chemistry and green engineering principles should be used.

- Biomimetic approaches should be used.

- Surface texturing should be applied to control surface properties.

- Environmental implications of coatings should be investigated and taken into consideration.

- Design for degradation of surfaces, coatings and tribological components.

- Real time monitoring

- Sustainable energy application.

Greater fuel economy is important from the view points of natural resource conservation, environmental protection, and economic benefits. But environmental regulations cover a large range of issues beyond fuel economy. Regulations include not only those affecting auto tailpipe emissions but manufacturing plant emissions, recyclability issues and replacement refrigerants for CFC's also. It is also 
A Study on Development of Industrial Tribology in India with some Future Prospects

mandatory that some currently successful tribological solutions must be replaced.

\section{TRANSMISSION TRIBOLOGY}

In transmission, one area full with tribological complications is the application of toroidal traction drives. Continuously variable transmissions (CVTs)[5] offer significant energy saving by enabling crankcase engines to operate closer to their optimum performance level over a full driving cycle. At present, most vehicle CVTs in use are belt drives and these are limited in torque capability to use in relatively low capacity engines. CVTs based on counter formal contact, in particular with a toroidal geometry[6], offer higher torque capability and could thus be used in larger engine cars and even trucks. There are currently two challenges faced by traction drives from tribological research point of view. One is to produce lubricants able to provide high friction or 'traction' over the wide temperature and pressure range experienced in EHD contacts. Most conventional lubricants reach limiting EHD traction coefficients at high pressures. To transmit power through an EHD contact requires higher traction coefficients and, over the years there have been considerable efforts to develop synthetic lubricants with very high traction coefficients values, i.e. 'traction fluids' [7]. However these remain costly and have limited traction at high temperatures.

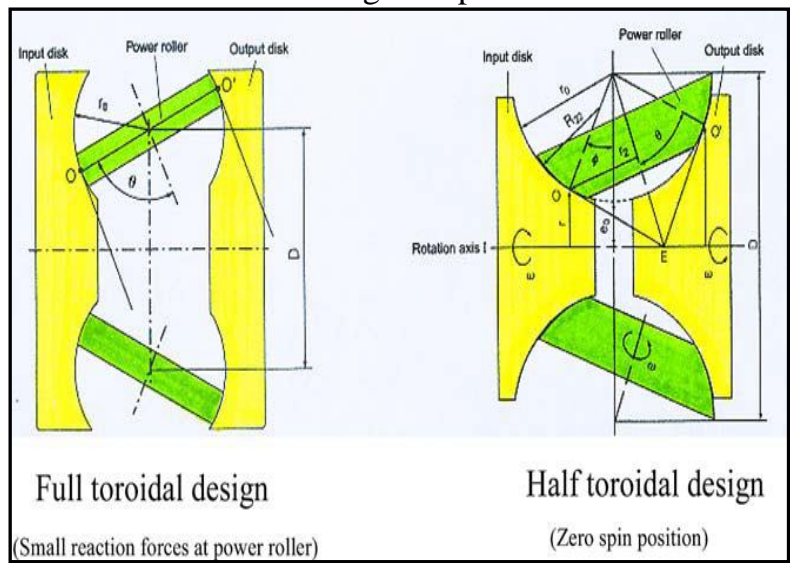

Fig. 2 : Toroidal geometry

A second challenge is to develop accurate rheological models of fluid behavior in EHD conditions. Many such models have been proposed which can, in theory at least, be used to predict EHD traction. However, there are still areas of crucial disagreement between these. Some, based primarily on EHD friction studies, suggest that, as shear stress increases, the fluid first shear thins and then eventually yields completely at a limiting value of shear stress.

A modern automatic transmission is often equipped with a slipping torque converter clutch in order to improve fuel economy. The fuel economy benefits comes from a reduction in fluid coupling energy losses in torque converter. Friction- induced vibration protection is crucial for successful implementation of this design.

\section{TIRE TRIBOLOGY}

Technological advancements world over is a phenomenon witnessed in all products, processes and services. Automotive industry is not different and what we see today is nothing but enormous pace of these developments forcing Tire industry also to proliferate and augment their technology base. To complete these changes, the growth in infrastructure (better road/ expressways etc) has further underlined the need for tire manufacturers to adopt and upgrade the system to meet world class performance yardsticks.

When it comes to recognizing the most important customer requirement, manufacturers has always emphasized "safety" as the prime requirements. Tire is the only contact of the vehicle with the ground. All types of forces (traction, cornering, braking etc) are transmitted to the ground through this contact only. So, it entails enormous efforts on tire manufacturer to deliver safety. The focus on safety aspect for the customer begins at drawing board stage itself. Safety is designed into products by way of usage of most advanced materials, cutting edge technology and state-of-the-art manufacturing facility. Safety is measured at every stage of tire development by way of adopting established safety factors during the engineering of tire; evaluation of pilot products on indoor testing machines with stringent criterion and finally by targeting the shorter braking distances for dry as well as wet applications. The braking distance tests are being conducted involving GPS (satellite) technology at world's best proving grounds on variety of road surfaces. Tires are also known for safest behavior in hard cornering even at high speeds. The tread designs are preferred not only for aesthetic reasons but also for better grip, good directional stability \& control and easy removal of water which prevents aquaplaning at high speeds. Many manufacturers are promoting in a big way the use of tubeless tires in place of tube-type tires for enhanced safety because there is no sudden loss of inflation on tubeless tires, hence vehicle doesn't lose control.

Other critical parameter of a tire is its behavior on wet road, especially in hilly areas where the roads remain wet for most of the year. The traction (grip) mechanism of a tire on dry surface and on wet surface is entirely different. Traction properties of a tire define its braking, grip and high speed cornering performance. A tire having a good dry traction will not necessarily have a good wet traction. Manufacturers has adopted the world's most advanced compound technology- Silica compounding which uses surface activated silica as the reinforced filler in the tread compound and gives excellent wet properties with enhanced dry traction. Thus these products are superior in performance on both dry and 
wet roads. Silica technology in compounding when coupled with snow \& ice friendly tread designs, results in development of "winter" tires which are good on wet surfaces also. With fuel prices soaring any innovation that helps reduce a vehicle's fuel consumption is valuable. The good news is that by replacing some of the traditional carbon black compound with silica we will substantially reduced the rolling resistance of tires. In fact tests indicate that, provided the tires are maintained at the correct pressure the silica compound will reduce rolling resistance by $20 \%$ or more. This means that less fuel is required to propel the vehicle forward with a $20 \%$ reduction in rolling resistance translating into a $5 \%$ reduction in fuel consumption. That's a significant saving.

\section{VII.EDUCATION AND INDUSTRY}

Education and industry are closely inter-related to each other. For any industry to flourish new innovations are required. Here comes the role of education in providing such innovative techniques to industries. Education has been playing its vital role by providing a large number of engineers and scientists every year at graduate level. In India a vast infrastructure of engineering colleges, numbering in tens of thousands, imparting engineering education. Graduates from these colleges go to man industry. Tribology is not a subject in curriculum but despite of that basic knowledge of engineering equip these student to pick the practical tribology well in when needed in industry. Some attempts have been made at master's level by some IIT to introduce Tribology and with success graduates are holding senior position in R\&D.

The relation between industry and education appears but with the small time motive of solving small problems. Education has great role to play in the development of nation. Despite of so much government aid, work in the research field is quite less. A few works has been done in the field of wear/tribology, biomaterials and nanotribology. Still a long way to go.

\section{FUTURE TRENDS}

Industrial Tribology is now under development, and it will make great advancements in nearby future. Some of the most promising fields on the basis of present development are as follows.

- Green tribology:- Tribological investigation for the purpose of environment protection. Mitigating the pollution, solid waste, noise level are interesting areas to work on for future.

- High-Tech IT field:-Tribology in technical components. There is a great scope due the reduction in the size of components. As smaller components need more sophisticated process of lubrication and all.

- Advance and reliable tools:-Due to utilization of new materials and techniques new reliable tools are also needed to get reliable and accurate product.

- Space Tribology:-In the era of high-tech communications, space Tribology is one the premium field of Tribology to work on.

\section{REFERENCES}

[1] Sanjay Kumar Biswas: Research and development in tribology in india.

[2] Ponnekanti Nagendramma, Savita Kaul: Development of ecofriendly/biodegradable lubricants: a review.

[3] Tung, S.C and McMillan M.L: Automotive tribology overview of current advances and challenges for the future.

[4] Kluger M, Fussner DR. An overview of current CVT mechanisms, forces, and efficiencies.

[5] Michael Nosonovsky and Bharat Bhushan. Green Tribology: principles, research areas and challenges.

[6] Hugh Spikes: Tribology research in the twenty-first century

[7] Dare-Edwards MP and Mead HB: A novel family of traction fluids deriving from molecular design.

[8] Tsubouchi T, Hata H, Yamada H, Aoyama S. Development study of new traction fluids for automotive use.

[9] M.F Wani and O.P Gandhi: Maintainability design and evaluation of mechanical systems based on Tribology. 